\title{
Trench Traffic: David Jones's In Parenthesis
}

At the conclusion of the 'Preface' to In Parenthesis (1937), his modernist epic about an infantryman's experiences in the First World War, David Jones explains that he chose the poem's title 'because I have written it in a kind of space between - I don't know between quite what'. 'For us amateur soldiers', he goes on,

the war itself was a parenthesis - how glad we thought we were to step outside its brackets at the end of ' 18 - and also because our curious type of existence here is altogether in parenthesis.

The manifold evocations of liminal space with which Jones ends his prefatory note are an aspect of In Parenthesis towards which critics have frequently been drawn. For Tyrus Miller, Jones's 'space between' is 'a rebus of his deep perplexity about where to stand as a writer in the postwar world' ${ }^{2}$ for Stephen Kern, it represents how the experience of modern warfare 'clamped the soldier in the present as if bracketed from past and future' ${ }^{3}$ But what affinities might we also find between Jones's metaphorical 'space between' and the physical sites on the Western Front where he himself served and in which In Parenthesis unfolds? As Part 1 of the poem ends, with Jones's fictional battalion arriving in northern France, the concluding image is one of uneasy adjustment, as British soldiers take in the alien environment that will be their home for years to come:

Toward evening on the same day they entrained in cattle trucks; and on the third day, which was a Sunday, sunny and cold, and French women in deep black were hurrying across flat land - they descended from their grimy, littered, limb restricting, slatted vehicles, and stretched and shivered at a siding. You feel exposed and apprehensive in this new world. (9)

Disembarking from a train that has transported them through the night, two days since departing from an unnamed English port, these infantrymen struggle to make sense of the 'new world' of modern warfare as they step inside the 'brackets' described by Jones in his 'Preface'. In placing this disorienting sensory experience as the culmination of three days' travel on foot, boat, and train, In Parenthesis associates mass transit and psychological transition as fundamentally linked to the poem's exploration of the 'space between'.

Recent work in modernist studies has frequently engaged with spatial dynamics as an integral structuring principle of texts, focusing on what Andrew Thacker in Moving Through Modernity (2003) terms the 'identification of place and actualisation of space [...] the twin poles around which the spatial stories of modernism operate'. ${ }^{4}$ For Thacker, the emergence of modern transportation systems is inherently bound up with the changing perception of space that he traces in twentieth-century literature. However while literary geography has focused on urban centres as the sites of modernist spatial consciousness - with particular emphases on New York, Paris and London - the topography of the Western Front has remained largely ignored. In this essay I argue that the experience of the First World War as represented in Jones's In Parenthesis is characterised by both a meticulous detailing of trench geography and moreover by a keen awareness of the 'space between' that modern warfare temporarily creates. In Part 4 of the poem, the platoon is still adapting to the 'new world' they first confronted some eighty pages earlier: 
They wondered how long a time it took to become so knit with the texture of this countryside, so germane to the stuff about, so moulded by, made proper to, the special environment dictated by a stationary war. (91)

After the 'Race to the Sea' and the First Battle of Ypres in 1914 failed to yield a decisive victory for either the Allied Powers or Germany, the trench system that developed on the Western Front - initially conceived as temporary yet ultimately the conditioning factor of the war's four-year duration - grew into a massive infrastructure that required continuous supply. ${ }^{5}$ The 'special environment' that Jones describes remained almost entirely 'stationary', but traffic - of soldiers and vehicles, supplies and ammunition, information and communications - continuously operated within it, from it, and to it. Martin Van Creveld has described the systems of transit that developed to support the Western Front as 'the greatest logistical revolution of all time'. ${ }^{6}$ As this essay demonstrates, the common conception of traffic as a uniquely metropolitan phenomenon is extended by Jones into one peculiarly applicable to the experiences of those who lived within these vast networks of supply. In its representation of multifarious forms of wartime traffic and the incessant movement of its characters within this 'stationary war', Jones embodies the peculiar 'texture of this countryside' in the textual space of In Parenthesis itself.

Jones enlisted in the $15^{\text {th }}$ Battalion of the Royal Welch Fusiliers on 2 January 1915, arriving in France in December of the same year. He served in the Richebourg Sector of the Western Front until June 1916, when his battalion moved south to engage in the opening stages of the Battle of the Somme; he was wounded during an assault on Mametz Wood on 10 July 1916 and extracted back to England immediately afterwards. ${ }^{7}$ Although after recuperating he would continue to serve as a private for the war's duration, the narrative of In Parenthesis ends with this assault on Mametz Wood. By the time of Jones's arrival in France at the end of 1915, the size of the British Expeditionary Force there had more than trebled since his enlisting, from 300,000 troops in January to just under one million in December. Already at this nascent stage in the conflict, approximately 220,000 animals, 460,000 tons of forage, 305,000 tons of food, 120,000 tons of ammunition, and hundreds of thousands of tons of other supplies had been landed in France from Britain and transported from base ports to the front line. ${ }^{8}$ These numbers would increase dramatically from 1916 onwards, as the ammunition supply and casualty evacuation necessitated by the Somme and other offensive strategies pushed the transportation system to breaking point: it is this historical moment that Jones in his 'Preface' describes as when 'things hardened into a more relentless, mechanical affair' and when the 'wholesale slaughter' of modern warfare fully emerged (ix).

Although dates and place names are rarely given in Jones's poem it is, as Thomas Dilworth has observed, 'generally historically accurate' as a record of his own experiences in France. ${ }^{9}$ What is striking however is that In Parenthesis is a First World War poem that begins not on the Western Front but in England, not in the otherworldly environment of the trenches themselves but with the journey to them. Part 1 of the poem records the chronic exhaustion of three days' movement: the 'considerable distance' of the battalion's journey 'through miles of dock', 'their sea weariness, their long cramped-upness and fatigue' when aboard ship, and the 'grimy, littered, limb restricting, slatted vehicles' in which they entrain across France (7-9). This exhaustion is underscored by the parataxis of Jones's phrases such as those just quoted, which in their accrual of descriptive material syntactically mirror the cumulative strain of the journey. Moving each division of the British Expeditionary Force to the front line was, as Jay Winter details, a serious undertaking:

Getting to the Front was certainly not half the fun [...] The problem was the sheer size of the units to be moved. A division of approximately 12,000 men, with its horses, stores and 
equipment, took up (according to some estimates) over 1,000 railway cars; getting it all on and off at appointed times were monumental tasks [...] Fully disgorged from a train, a division took up fully $24 \mathrm{~km}$ ( $15 \mathrm{mi})$ of road, and it took about five hours for the whole parade to pass one spot. ${ }^{10}$

The comparison Winter tacitly evokes here between the vast infrastructure of rail carriages and the serpentine troop columns themselves is rendered explicit in In Parenthesis's opening pages. Still inexperienced in the discipline of soldiering, the privates' incompetent march morphs abruptly into an image of mechanised transportation being similarly put under strain:

In ' $\mathrm{D}$ ' Company round the bend of the road in the half-light is movement, like a train shunting, when the forward coaches buffer the rear coaches back. The halt was unexpected. (5)

Movement on this scale shifts the individual infantryman's consciousness into part of a larger unit, one which must negotiate the traffic jams at crossroads that one would not normally associate with travelling on foot: 'They revived somewhat, and for a while. Yet still these interminable ways between - these incessant halts at junctions' (7). It is cessation that becomes 'incessant', the 'ways between' both perpetual and interminably monotonous.

In an autobiographical piece first published after Jones's death, he recalls that 'my first remembered thing was in 1900, or about 1900', when 'an unfamiliar sound from the roadway outside impelled me to creep out as cautiously as I could and make for the window',

what I saw and heard was a thing of great marvel - a troop of horse, moving in column to the taratantara of bugles. It was in fact a detachment of the City Imperial Volunteers on a recruitment ride through the outer suburbs for the war in South Africa of which I was, as yet, in blissful ignorance. But to me, those mounted men were a sight of exceeding wonder, and I said to myself: 'Some day I shall ride on horseback', a desire never to be realized, to my continued regret to this day. ${ }^{11}$

Inspired by this childhood memory at the outbreak of the First World War, when Jones first went to enlist he requested to join the Royal Welsh Yeomanry, only to be turned down for his never having ridden a horse. Though never fulfilled, his desire takes on a particular irony when considered in light of the technological transformation that warfare would undergo in the years 1914-18. By the end of the conflict a cavalry unit would be unthinkable and its memory consigned to the tactics of the Second Boer War, the preparations for which comprised the earliest recollection of a four-year-old David Jones. His reason for omitting his wartime experiences in the post-Somme years from In Parenthesis is raised at the end of this autobiographical writing, just as it is in his 'Preface': 'the increased use of mechanical transport, and mechanization in general, made the whole "feel" very different from the war I had known in the months before the Somme battle'. ${ }^{12}$ The arrival of modern warfare and its contrast with earlier campaigns occupied a significant place in his imagination. While the narrative of In Parenthesis deliberately eschews mechanised war's complete emergence, it does however, incessantly figure the transition to it, mapping as it does so the shift in consciousness that modern warfare entailed.

In a letter from 1938, a year after the publication of In Parenthesis, Jones wrote of it as 'chained to a sequence of events', recalling both the poem's narrative linearity and the mass transportation systems with which it opens. ${ }^{13}$ The subsumption of the individual into the movements of the crowd is integral to Jones's portrayal of twentieth-century soldiering. Private John Ball - the work's protagonist and one of several fictional surrogates for Jones 
himself - learns to adapt to this form of motion in the poem's early sections, 'as his loaded body moved forward unchoosingly as part of a mechanism another mile or so' (19). Further on in the narrative when they are more accustomed to this particular mode of movement, his platoon's alteration is apparent:

Feet plodding in each other's unseen tread. They said no word but to direct their immediate next coming, so close behind to blunder, toe by heel tripping, file-mates; blind on-following, moving with a singular identity. (37)

Succinctly evoking both the 'tread' of footsteps and that of wheels, the column of troops is technologically refigured as a 'singular identity' that moves through the night. As a message is passed back for the platoon to halt, each individual stops in automated succession:

He just muttered halt without a turn of the head.

Get on get on - we'll lose connection.

They've halted I tell you, pass it back.

Dark chains of whisperings link by link jerked each one motionless. (38)

Jones's later description of the poem's 'chained' narrative finds precedent here in the 'dark chains of whisperings' that halt each 'link' in turn, recalling too the couplings which connect a railway's rolling stock. No longer 'like a train shunting' as they were first described but now like a train halting, the soldiers' systemised movement is gaining efficiency as their experience proceeds.

While burgeoning supply lines and the ever-increasing transfer of troops was leading to vast growth in rail and motor traffic in northern France, on the Home Front, by contrast, there was a noticeable change in the opposite direction. In H. G. Wells's Mr Britling Sees It Through (1916) the novel's protagonist drives through Trafalgar Square in the early days of the war, perceiving as he does so a marked difference in the culture of the capital's streets:

His impression of the streets he passed was an impression of great unrest. There were noticeably fewer omnibuses and less road traffic generally, but there were a quite unusual number of drifting pedestrians. The current on the pavements was irritatingly sluggish. ${ }^{14}$

Britling's observation is not just idle speculation but reflects a broader shift in London's transport infrastructure during this period. In the war's opening stages the War Office requisitioned 1319 of the buses owned by the London General Omnibus Company, over a third of their total stock. ${ }^{15}$ Painted grey and shipped across the channel, they were converted into troop carriers to ferry soldiers around the front lines. This peculiar phenomenon was one Jones experienced first-hand, as his battalion rode these vehicles in the penultimate stage of their journey to the trenches, ${ }^{16}$ an experience which is recalled in the second section of In Parenthesis:

By a building of red brick, fronted with a yard, busy with carts and blue-trousered men moving casks - the sound of a hydraulic mechanism within - a traffic-control officer watched the last files of the rear company lurch up with all their gear; pack the outside seats.

He waited until the last grey 'bus moved eastward with its load, and went back to breakfast. (18) 
By delaying clarification that this 'sound of a hydraulic mechanism' is in fact that of a London omnibus repurposed for front-line duty, the passage emphasises the particular oddity that this mode of transport should appear so far away from its normal route. As we approach the front line, the introduction of a traffic-control officer and the appearance of a metropolitan vehicle both indicate the surreal atmosphere of the trenches that In Parenthesis will repeatedly convey.

While accurately reflecting the journey undertaken by Jones and the Royal Welch Fusiliers in December 1915, the embarkation of the battalion upon this cosmopolitan mode of transportation as they approach the front intimates a sense of urbanity integral to Jones's presentation of trench life. As Charles Andrews notes, In Parenthesis 'renders [...] battlefields metropolitan' and turns 'war-torn trenches into sanctified city'. ${ }^{17}$ The historical reality that a fleet of a thousand buses served the trenches - muted in colour yet otherwise identical to those that operated in London just a year earlier - encapsulates how the Western Front could appear to be a ghostly version of the capital itself. In the seminal study The Great War and Modern Memory (1975), Paul Fussell identifies several aspects of this phenomenon, noting how 'directional and traffic control signs were everywhere in the trenches, giving the whole system the air of a parody modern city', further heightened by routes being titled after 'place or street names with a distinctly London flavor' ${ }^{18}$ Upon first arriving in the trenches, John Ball feels he can 'sense here near habitation, a folk-life here, a people, a culture already developed, already venerable and rooted' (49). The 'culture' of this sector, as the plethora of Cockney voices that punctuate Jones's text suggest, has its roots in England's capital. Despite his unit being titled the $15^{\text {th }}$ Battalion (London-Welsh), it contained relatively few of the latter group. As Jones himself notes in his 'Preface': 'as Latin is to the Church, so is Cockney to the Army, no matter what name the regiment bears' (xii).

By consulting trench maps of the area of the Richebourg Sector in which Jones served, we can see the extent to which London-inspired names dominate its recently formulated topography. ${ }^{19}$ Two permanent roads that existed prior to the system's construction are renamed Edgware Road and Oxford Street, while other trenches include Bond Street, Vine Street, and - appropriately parallel with a trench railway - Euston Road. By superimposing onto the French landscape a radically different cartography with names imported from Britain, the trench map represents a palimpsestic rewriting of an existing geographical location to create a 'space between'. In his study of First World War trench names, Peter Chasseaud argues that this practice instilled in soldiers a 'capability to co-exist physically and mentally in two quite different places', a custom that 'made bearable the unbearable'. ${ }^{20}$ This practice of mapping was also one that Jones himself was readily familiar with. During his second tour of the Western Front from late 1916, he spent several months attached to the $2^{\text {nd }}$ Field Survey Company of the Royal Engineers, observing enemy trenches. ${ }^{21}$ For this he underwent training in surveying and map reading, a process that, as Thomas Dilworth writes, 'intensified his spatial imagination in ways that would influence his art'. ${ }^{22}$

For the original 1937 edition of In Parenthesis, Jones included in its notes a hand-drawn map of the Richebourg Sector, one which he explains as having been 'made by the author from his own convenience when writing' and which was 'roughly copied from a map of much later date than the period of the text'. ${ }^{23}$ Given that Jones has inscribed the same date and scale on his drawing as those listed on the General Series map to which I have just referred, it seems likely that his copy is taken from it. His sketch includes all of the London place names listed above and underlines that spatial awareness that he desired In Parenthesis to convey, with the battalion's first route through the trenches precisely mapped out.

As they descend from the bus that has transported them closer to the front line, Jones's soldiers undergo a further sense of disorientation, experiencing 'in their nostrils an awareness and at all their sense-centres a perceiving of strange new things' (18). Yet this landscape, 
though strange and new, engenders too a sense of recognition: 'It was not that the look of the place was unfamiliar to you. It was at one to all appearances with what you knew already.' This disorienting sense of the platoon being at once rootless and rooted is particularly heightened by the irony that the vehicle from which they descend is one they would previously have ridden at home. Later in the poem upon their entering the trench system, directions are barked that confirm this sense of 'what you knew already':

You've lost your guide - you can read the map, anyway, it's a plumb straight road you've three hundred yards to the communication trench - turn left into Sandbag Alley right at the O.B.L. - left into Oxford Street - get along quickly - he has us enfiladed. (40)

Although throughout most of In Parenthesis place names are deliberately avoided, it is upon arriving in the trenches that they begin to occur with startling regularity. Incorporated among names such as the Old British Line and Sandbag Alley that we may be more accustomed to expect, the sites of London abruptly intrude, shifting the perspective of soldier and reader alike:

R.E.s, sir - yes sir, Sandbag Alley - leads into the O.B.L. sir - water-logged all the way sir - well above the knee sir - best keep the road - turn off left at Edgware, right at Hun Street sir - straight to the front line sir (43)

As they struggle through flooded trenches, these in turn are metaphorically reconfigured as further modes of transportation: 'Edgware Trench, like a river's lock-gates, marked a new mood for the highway, which bore on still slowly' (44). Yet the trench infrastructure, however weather-beaten, offers some sense of direction in contrast to the uncertain landscape which surrounds it:

The road, broken though it was, seemed a firm causeway cutting determinedly the insecurity that lapped its path, sometimes the flanking chaos overflowed its madeness, and they floundered in unstable deeps (41)

Through the structure of its 'madeness' and its symbolically titled routes, the trench system counters the instability of war itself.

Of the many anonymous voices that intrude upon the narrative in this first experience of the trench system, one clarifies the reason for the enemy's use of High Explosives in this particular sector: 'He's on Mogg's again - he's using H.E. - hope to christ the relief's through - it's that blasted Euston Road tramway that attracts him' (44). Mogg's Hole - a position in the Richebourg Sector where a light railway and the Euston Road trench converge - is the subject of enemy shellfire as one of several supply lines to this particular area. Trench railway systems were arguably the most important aspect of transportation in the First World War: $60 \mathrm{~cm}$ narrow gauge railway lines could be built rapidly and easily reconstructed if shelled, enabling continuous supply of the front line. British HQ had begun to support the introduction of light railway in September 1915, before fully endorsing the initiative in February 1916. ${ }^{24}$ As John Ball's battalion move towards the front, their march is halted at a crossroads by an encounter with one of these trains:

There was a temporary halt where a light railway met the road. Trucks filled with the very new clean deal planking, stakes of pine, stacked neatly up, wooden frames, bales of wirenetting and other wire, hedge-hog like, in balls; a rigid medley thrown about - iron and wood and iron, made evidently to some precise requirement, shaped to some usage yet 
unknown to any of that halting company; who looked on wonderingly, with half inquisitive, half fearful, glancing. Anyway they wouldn't have railways very near the line - would they. (19-20)

Apprehensive as to what purpose this assortment of 'iron and wood and iron' may serve, the soldiers console themselves that such railways cannot surely extend to the trenches. The fact that light railways were indeed capable of reaching almost to the front line, far further than a standard gauge train could, was integral to the military maintaining its positions.

Jones's fictional platoon will later realise that this is the case. As he stands sentry on his first night in the trenches, John Ball overhears both forms of supply train working in unison, feeding the war machine for the following day's hostilities:

He heard, his ears incredulous, the nostalgic puffing of a locomotive, far off, across forbidden fields; and once upon the wind, from over his left shoulder, the nearer clank of trucks, ration-laden by Mogg's Hole. (50)

While the 'far off' sound of the steam train may carry a 'nostalgic' reminder of Ball's journey here or of the railways in Britain, the 'clank' of the trench railway carrying supplies to the front soon brings him back to the modern business of soldiering. The quantity of goods carried by the railways during the First World War was, as has already been mentioned, a logistical undertaking greater than any that had gone before. In May 1916, with its railway system under increasingly heavy strain, the French suggested that the British provide all the wagons required for the movement of their own troops and supplies: this amounted to a total of 22,500 railway trucks. Over the course of the war, the British built around 800 miles of railway, the French over 3,500. ${ }^{25}$ The soldiers of In Parenthesis are always conscious of this nightly method of resupply, as 'ill-oiled wheels screech on quiet nights when they bring the ration trucks from Richebourg of the Vow' (88).

The combination of this vast railway infrastructure and the Western Front's artificial reminders of London produced the historical phenomenon identified by Fussell when he writes that 'what makes experience in the Great War unique and gives it a special freight of irony is the ridiculous proximity of the trenches to home' ${ }^{26}$ Separated from Britain by only the twenty-mile wide English Channel and with trains enabling the rapid transportation of personnel and communications, many soldiers experienced what Fussell terms the 'ironic close exile' of trench life. ${ }^{27}$ By 1917 over eight million letters were sent home from the Western Front each week, with relatively fast delivery allowing, as Michael Roper writes, 'correspondents to establish regular routines for keeping in contact' which 'intensified the feeling of proximity'. ${ }^{28}$ In Parenthesis establishes this routine as a rite of passage, it being the only activity described from the platoon's first day in France:

In the morning, they were given Field Service postcards - and sitting in the straw they crossed out what did not apply, and sent them to their mothers, to their sweethearts. (8)

During periods of rest soldiers take the opportunity to 're-read yet again the last arrived letter' (94), while John Ball at one point receives a 'satisfactory parcel from his aunt in Norwood' (117). Moments such as these underscore a sense of liminality, one made all the more palpable by the poem's atmospheric rendering of London phenomena on the front line.

As the war progressed and leave periods became more standardised, the railway stations of London took on a further sense of intermediacy, being both the gateway for those arriving on leave and for those departing to the Front once more. As Adrian Gregory observes, 'the 
transition from the front to London was remarkably rapid', resulting in sensations being carried over from one space into another:

The strains of combat were not always left behind [...] a soldier suffered a flashback as he was entering the tube and believed himself to be storming a bunker. He fixed his bayonet and charged the ascending crowd. ${ }^{29}$

Jones would comment about his own time on leave that he could 'hardly endure it at all because you couldn't make people understand anything' of life at the front. ${ }^{30}$ As Thomas Dilworth remarks, it was an 'ambiguous and curiously unsettling' experience for him. ${ }^{31}$ Yet in his poem the proximity of England to the Western Front is poignantly recognised, when a vantage point behind the line allows each soldier to turn 'his head toward the left, toward north west, a toward-home glancing, back down the broken avenue',

Extending fields spread flatly, far to either side, uninterrupted to the sight, not any longer barriered nor revetted in. It was a great goodness in their eyes, this expanse, they drank in this visual freedom gladly, and were disposed to linger before dropping one by one down, where Sandbag Alley meets the road on the north-east side. With that descending this gate to their prison-house of earth closed-to, which had momentarily stood ajar, tantalisingly upon the western escape (91-2)

This moment of 'toward-home glancing' is brief but the significance attached to the 'visual freedom' it affords is striking, as is the fact that it abruptly ends when they climb back into the trenches below.

Just as Gregory's example demonstrates how experiencing a London Underground station psychologically resituated a soldier back on the front line, In Parenthesis relocates the London Underground in the trenches themselves. On a break between duties, Ball's platoon are interrupted by an officer who questions them in a particularly haughty manner:

A young man in a British warm, his fleecy muffler cosy to his ears, enquired if anyone had seen the Liaison Officer from Corps, as one who asks of the Tube-lift man at Westminster the whereabouts of the Third Sea Lord. Vacant faces turned to him. He was advised to try Mr. Jenkins in the sap. (97)

Surreal though this comparison is, it comes just shortly after the platoon's descent from the 'visual freedom' they drank in above ground to their 'prison-house of earth closed-to'. By placing Ball and his companions in the position of the 'Tube-lift man', the image associates their underground existence in the trenches with the subterranean movements of the London Tube. This comparison is not just confined to In Parenthesis. After Jones returned from the war, the Underground would recur in his letters as a metaphor for a peculiar sense of discomfort he felt in Britain. Given the belatedness of Jones writing In Parenthesis - he did not begin until 1928 and it was not published until 1937 - his postwar experiences inevitably fed into his depiction of the First World War. In 1935, in a discussion of Malory's Le Morte d'Arthur, he mentions in passing 'the sense of imminent ruin in the space of the Hampstead tube lift' ${ }^{32}$ Although seemingly a throwaway comment, it is echoed in a letter of 1940, in which Jones muses upon how in the air raids on London in the Second World War 'that low whine and dull thud away in the distance reminded me of my first shell in Xmas 1915'. He continues, 
I don't think the human race will ever get adjusted to 'explosions'. They are bad for the human mechanism, and just as the tube-lift gives one a nasty feeling in the stomach directly assaults the central nervous system, so does the explosive ${ }^{33}$

Jones's description of an explosion's impact being an assault on the 'human mechanism' is particularly striking, recalling the mechanised forms of modern warfare that he had experienced years earlier in the First World War. But so too is his admission in both letters that it is the 'space' of the tube lift in which he himself feels particularly uneasy. It is just one aspect of how the London Underground would continue to remind him of his time in the subterranean world of the Western Front years after it ended. As Thomas Dilworth writes about Jones's return to London after the war, the city 'seemed like an alien place, except for the screaming of tram-cars, which sounded exactly like in-coming shells' ${ }^{34}$ For Jones, the traffic of the trenches would never be confined to that particular historical moment. The 'space between', like the 'the space of the Hampstead tube lift', was a set of brackets he never truly stepped outside of.

${ }^{1}$ David Jones, In Parenthesis (1937; London: Faber \& Faber, 1963), xv. All further references will be given in the text.

${ }^{2}$ Tyrus Miller, Late Modernism: Politics, Fiction and the Arts Between the World Wars (Berkeley, CA: University of California Press, 1999), 32.

${ }^{3}$ Stephen Kern, The Culture of Time and Space, 1880-1918, revised second edition (Cambridge, MA: Harvard University Press, 2003), 292.

${ }^{4}$ Andrew Thacker, Moving Through Modernity: Space and Geography in Modernism (Manchester: Manchester University Press, 2003), 40. See also Peter Brooker and Thacker (eds.), Geographies of Modernism: Literatures, Cultures, Spaces (London: Routledge, 2005).

${ }^{5}$ See Hew Strachan, The First World War: Volume I: To Arms (Oxford: Oxford University Press, 2001).

${ }^{6}$ Martin Van Creveld, 'World War I and the Revolution in Logistics', in Great War, Total War: Combat and Mobilization on the Western Front, 1914-1918, eds. Roger Chickering and Stig Förster (Cambridge: Cambridge University Press, 2000), 57-72 (67).

${ }^{7}$ For biographical information here and throughout this article, I am indebted to Thomas Dilworth, David Jones in the Great War (London: Enitharmon Press, 2012).

${ }^{8}$ Ian Malcolm Brown, British Logistics on the Western Front 1914-1919 (Westport, CT: Praeger, 1998) 103.

${ }^{9}$ Dilworth, 'In Parenthesis as Chronicle', Poetry Wales 17:4 (1982), 37-45 (37).

${ }^{10}$ Jay Winter, The Experience of World War One (London: Macmillan, 1988), 129.

11 Jones, 'In illo tempore' (1975), in The Dying Gaul and Other Writings, ed. Harman Grisewood (London: Faber \& Faber, 1978), 19-29 (19).

${ }^{12}$ Ibid., 28.

${ }^{13}$ Jones, Letter to Harman Grisewood (31 May 1938), in Dai Greatcoat: A Self-Portrait of David Jones in his Letters, ed. René Hague (London: Faber \& Faber, 1980), 86.

${ }^{14}$ H. G. Wells, Mr Britling Sees It Through (1916; London: Hogarth Press, 1984), 230. My attention was drawn to this passage by David Welsh, Underground Writing: The London Tube from George Gissing to Virginia Woolf (Liverpool: Liverpool University Press, 2010), 162. Welsh's study also provides a fascinating account of the role of the London Underground in wartime London.

${ }^{15}$ T. C. Barker and Michael Robbins, A History of London Transport, 2 vols. (London: George Allen and Unwin, 1963-74), II. 192-4.

${ }^{16}$ Dilworth, David Jones in the Great War, 63. 
${ }^{17}$ Charles Andrews, 'War Trauma and Religious Cityscape in David Jones's In Parenthesis', The Journal of the Midwest Modern Language Association 40:1 (2007), 87-96 (87-8).

${ }^{18}$ Paul Fussell, The Great War and Modern Memory, revised third edition (Oxford: Oxford University Press, 2013), 46.

19 1:10,000 Regular Series Trench Maps: Series GSGS 3062 of the Geographical Section of the General Staff, War Office, London. 36 SW 3 Richebourg, Edition 9A (Secret), British trenches (blue) corrected to 9 September 1916, German trenches (red) corrected to 8 August 1916. Although this map postdates Jones's arrival in the Sector by nine months, the names of British trenches were not shown on earlier versions for fear of them falling into enemy hands. All trench names from In Parenthesis that are mentioned in the article correspond to sites on this map.

${ }^{20}$ Peter Chasseaud, Rats Alley: Trench Names of the Western Front, 1914-1918 (Stroud: Spellmount, 2006), 161.

${ }^{21}$ On this see Chausseaud, 'David Jones and the Survey', in David Jones: Artist and Poet, ed. Paul Hills (Aldershot: Scolar Press, 1997), 18-30.

${ }^{22}$ Dilworth, David Jones in the Great War, 170.

${ }^{23}$ Jones, In Parenthesis (London: Faber \& Faber, 1937), vi. The map appears between pages 192 and 193 of this edition. A copy of it is included in Dilworth, Reading David Jones (Cardiff: University of Wales Press, 2008), 50.

${ }^{24}$ Christian Wolmar, Engines of War: How Wars Were Won and Lost on the Railways (London: Atlantic Books, 2010), 169-72.

${ }^{25}$ Ibid., 180-1.

${ }^{26}$ Fussell, The Great War and Modern Memory, 69.

${ }^{27}$ Ibid., 71.

${ }^{28}$ Michael Roper, The Secret Battle: Emotional Survival in the Great War (Manchester: Manchester University Press, 2009), 50.

${ }^{29}$ Adrian Gregory, 'Railway Stations: Gateways and Termini', in Capital Cities at War: Paris, London, and Berlin, eds. Jay Winter and Jean-Louis Robert, 2 vols. (Cambridge: Cambridge University Press, 1997-2007), II. 23-56 (51).

${ }^{30}$ Jones, quoted in Dilworth, David Jones in the Great War, 130.

${ }^{31}$ Ibid.

${ }^{32}$ Jones, Letter to H. S. Ede (7 March 1935), in Dai Greatcoat, 65.

33 Jones, Letter to T. F. Burns (28 August 1940), in Dai Greatcoat, 101.

${ }^{34}$ Dilworth, David Jones in the Great War, 206. 